\title{
EFFECT OF E-LEARNING ON THEORETICAL-PRACTICAL LESSONS TRAINING TO PRODUCE LEARNING PROGRAMS
}

\author{
Dr. Maryam Golbabaei \\ Assistant Professor at Islamic Azad University \\ South Tehran Branch \\ Ma_Golbabai@yahoo.com
}

\begin{abstract}
The present research aims on effect of e-learning and traditional learning on training theoretical-practical lessons to produce curriculum programs in $\mathrm{McS}$ students of technology. Research hypotheses were proposed named as e-learning in training curriculum contents to produce training programs is more effective than traditional learning. Statistical population includes McS students and sampling include accessible sample by 50 students in 2 classes in which 25 students were test and control groups. The results by t-test showed that traditional training method act a little more successful.
\end{abstract}

Keywords: e-learning, traditional learning, training, curriculum programs production

\section{EXECUTION METHOD AND MEASURING INSTRUMENT}

The study Training Center Islamic Azad University, South Tehran branch, Faculty of Psychology has been done to remember the purpose of the study frequently in two ways, distance education, and training has been the traditional method of population included undergraduate students in 2014-2015 is a major educational technology in the school year. The sample consisted of samples available to 50 graduate student in theoretical practical training programs have been produced. The way it works is this the first students to draw in two classes for distance education and traditional choice and was replaced. The educational content to the training provided to them after training and test learning at this point, after 10 days, subject for students of both groups hypothesis in order to determine the test taught training was performed. This method has been implemented with the coordination with the remote test center, questions and names of 25 students in the experimental group were put at the disposal of the center of people be there on time students tested in 25 through the system of Boards were prepared to try on. Class education to students in traditional methods of teaching content through the sample 25 test sheets responded person in the School of Psychology. In addition, scores of students was determined after correcting papers. Distance learning classes, 25 students tested, at the appointed hour to provide name, national ID input specifications for online placement test on the network per day clock set, tested and responded to questions after the two-day score of students was sent via email to a researcher. Scores of both groups were analyzed statistically to evaluate and operations.

\section{RESEARCH INSTRUMENT}

To measure this, the researchers developed the test based on the content of the training was provided, was used and the scores that students gained from this test, the criteria for evaluating the effectiveness of the method is taught. This test has of the 20 question objective it was the kind of choice that classification is based on cognitive Bloom was set. Thus, the tests evaluated by the experts and content validity were necessary for its reliability using Cronbach's alpha coefficient equal action 0.91 respectively.

\section{FINDINGS}

After a test run by the researcher collected data (scores of students) using descriptive statistics (calculated central tendency and dispersion, prepared frequency distribution table presentations scores geometric 
data) were described then to infer statistical parametric $t$ test for independent samples (normal due to the frequency and distance of measurement scale score, the existence of two independent groups) were used. A 2-1-Training

Table 3.4 Distribution of distance learning student training score X2

\begin{tabular}{|c|c|c|c|}
\hline The frequency of density & $\begin{array}{c}\text { The frequency } \\
\text { percent }\end{array}$ & Abundance & Score \\
\hline & 8.0 & 2 & 13 \\
8.0 & 8.0 & 2 & 14 \\
16.0 & 24.0 & 6 & 15 \\
40.0 & 20.0 & 5 & 16 \\
60.0 & 28.0 & 7 & 17 \\
88.0 & 8.0 & 2 & 18 \\
96.0 & 4.0 & 1 & 19 \\
100.0 & 100.0 & 26 & Total \\
\hline
\end{tabular}

Diagram (4): Geometric representation of the distribution of student training score by distance learning

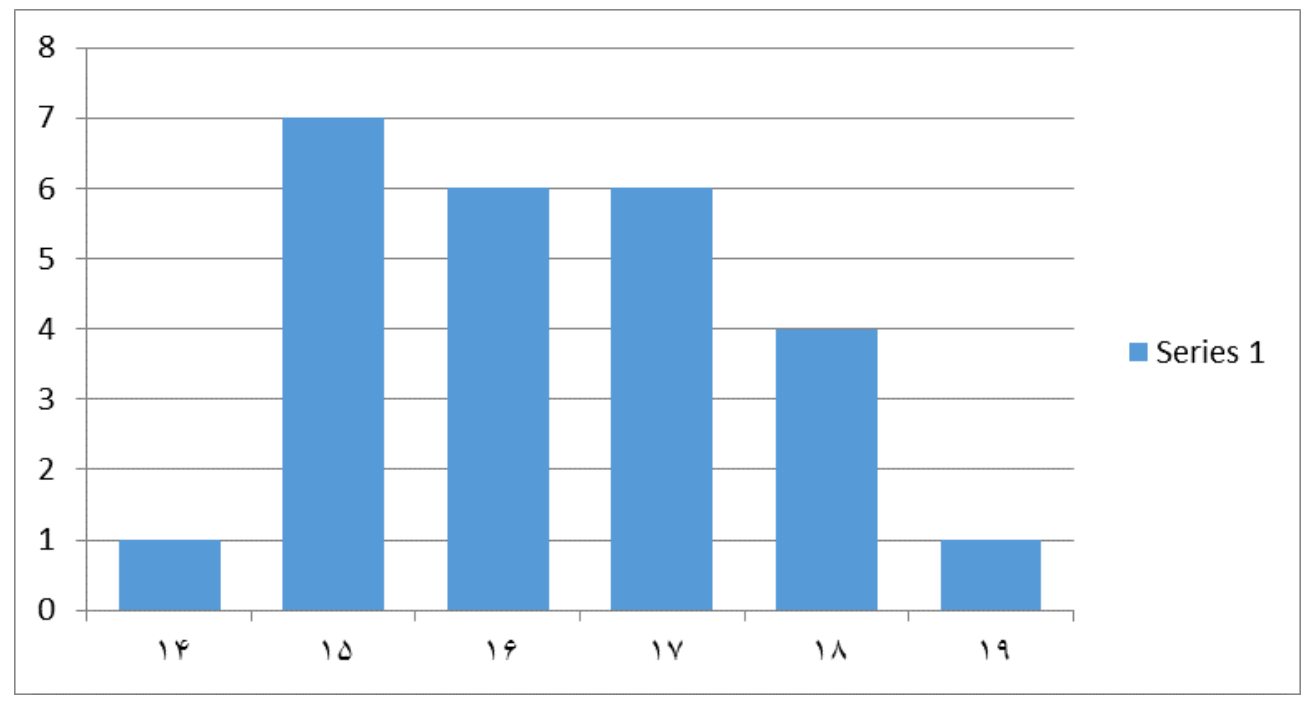

. Table 4-4 - central and dispersion descriptive indicators related to student training distance learning

\begin{tabular}{|l|l|}
\hline Training & Indicators \\
\hline $\mathrm{X} 2$ & \\
\hline
\end{tabular}




\begin{tabular}{|l|l|}
\hline & \\
& \\
25 & \\
15.92 & Number \\
305. & Average \\
$16: 00$ & Standard error of the mean \\
1.525 & Middle \\
2.327 & Standard deviation \\
$161 .-$ & Variance \\
464. & Degree of tilt \\
6 & The standard error degree of tilt \\
13 & variation range \\
19 & At least \\
398 & Maximum \\
\hline
\end{tabular}

The data presented in the above table shows that:

The minimum and maximum training of students score 13 and 19 and the average and median score of 15.92 and 16 respectively. Since the mean is smaller than the median, the distribution of scores is a negative tilt. However, not because of anything the degree of tilt $(-0.161)$ can be assumed normal distribution of scores training of students accepted distance education.

Table 7.4 Distribution of students using traditional learning X2 training score

\begin{tabular}{|c|c|c|c|}
\hline The frequency of density & $\begin{array}{c}\text { The frequency } \\
\text { percent }\end{array}$ & Abundance & Score \\
\hline & 4.0 & 1 & 14 \\
4.0 & 28.0 & 7 & 15 \\
32.0 & 24.0 & 6 & 16 \\
56.0 & 24.0 & 6 & 17 \\
80.0 & 16.0 & 4 & 18 \\
96.0 & 4.0 & 1 & 19 \\
100.0 & 100.0 & 25 & Total \\
\hline
\end{tabular}

Figure 6-4 Distribution of graphical representation, training scores of students with traditional instruction 
The Turkish Online Journal of Design, Art and Communication - TOJDAC July 2016 Special Edition

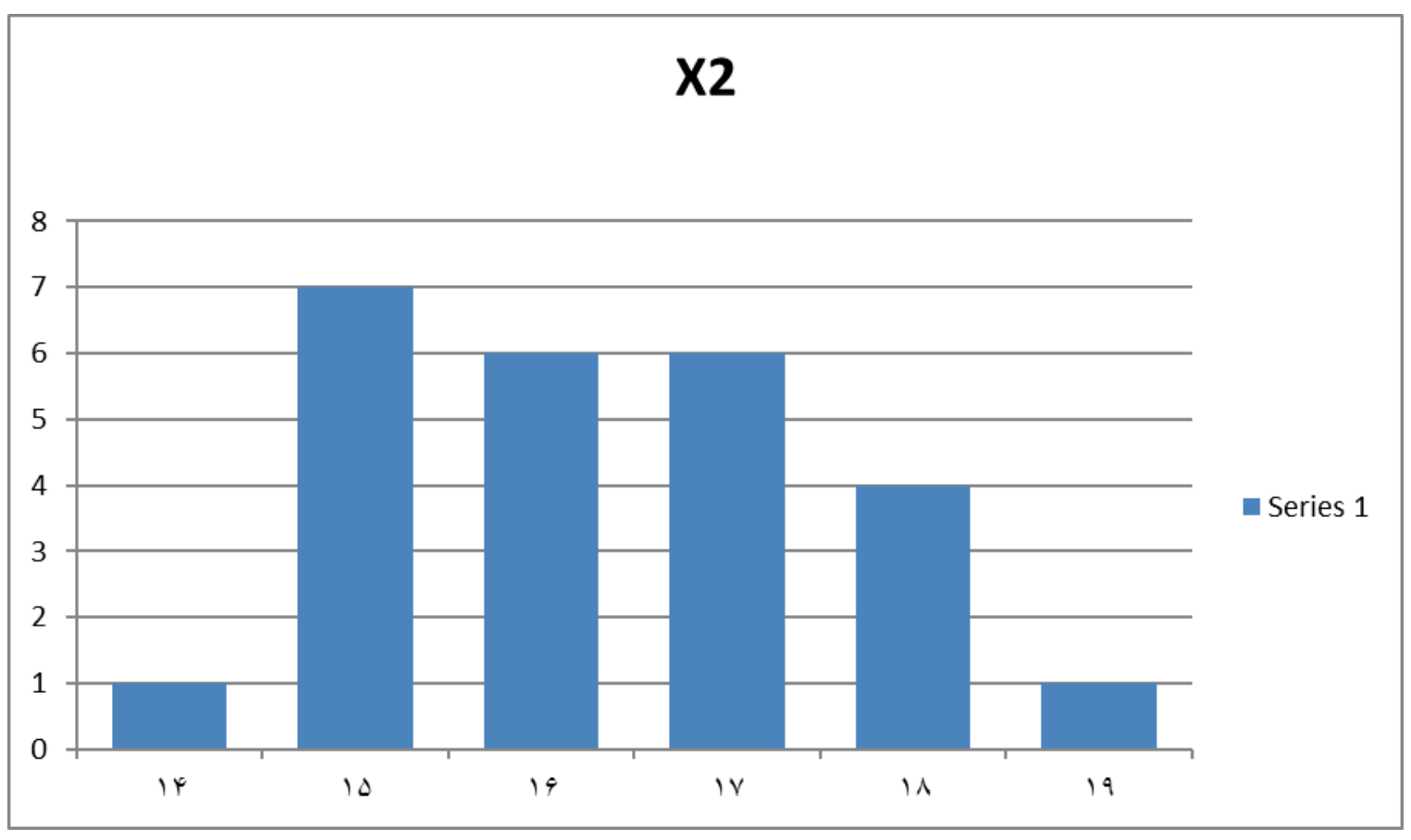

Table 8-4: central and dispersion descriptive indicators related to student training traditional learning

\begin{tabular}{|c|c|}
\hline Training & Indicators \\
\hline $\mathrm{X} 2$ & \\
\hline 25 & Number \\
$16: 32$ & Average \\
256. & Standard error of the mean \\
$16: 00$ & Middle \\
1.282 & Standard deviation \\
1.643 & Variance \\
243. & Degree of tilt \\
464 & The standard error degree of tilt \\
5 & variation range \\
14 & At least \\
19 & Maximum \\
408 & Total \\
\hline
\end{tabular}

All students with traditional learning

\section{A: 2.2 - Training}

The data presented in the above tables show that:

The minimum and maximum training score of respectively 14 and 19

The mean and median of the group respectively 16.32 and 16 stasis Since the mean is smaller than the median frequency distribution of scores is a negative tilt due to the insignificant degree of tilt training (0.243 ) can be assumed to be normal frequency of grade training curves were remote. 
Hypothesis: E-Learning course content production training programs in student training is more effective than traditional learning.

Table: 10-4- indicators independent groups $t$ test for comparison of training

\begin{tabular}{|c|c|c|c|c|c|c|c|c|}
\hline \multirow[b]{2}{*}{$\begin{array}{l}\text { Index } \\
\text { group }\end{array}$} & \multirow[b]{2}{*}{ Number } & \multirow[b]{2}{*}{$\begin{array}{l}\text { The } \\
\text { mean }\end{array}$} & \multirow[b]{2}{*}{$\begin{array}{l}\text { Standard } \\
\text { deviation }\end{array}$} & \multicolumn{2}{|c|}{$\begin{array}{c}\text { Levene test for equal } \\
\text { variances }\end{array}$} & \multicolumn{3}{|c|}{$\mathrm{T}$ test for equal medians. } \\
\hline & & & & $\begin{array}{c}\text { The } \\
\text { calculate } \\
\text { F value }\end{array}$ & $\begin{array}{c}\text { Significant } \\
\text { level }\end{array}$ & $\begin{array}{c}\text { The } \\
\text { calculate } \\
\text { t value }\end{array}$ & $\begin{array}{c}\text { Degrees } \\
\text { of } \\
\text { freedom }\end{array}$ & $\begin{array}{c}\text { Significant } \\
\text { level }\end{array}$ \\
\hline $\begin{array}{c}\text { Long } \\
\text { distance }\end{array}$ & 25 & 15.92 & 1.525 & & & & & \\
\hline Traditional & 25 & $16: 32$ & 1.282 & 0.057 & $\mathrm{P}>0.05$ & -0.096 & 48 & $\mathrm{P}>0.5$ \\
\hline
\end{tabular}

\section{RESULT}

Because the value of $t$ calculated from the $t$ represents the degree of freedom 48 to $95 \%(5.48 \%)$ is smaller, can be found that mean scores of two groups of students in distance learning Traditional learning, there is no significant difference. Therefore it can be concluded that the type of education

(Remotely Traditional) no significant impact on student training rates. So the hypothesis is rejected.

\section{DISCUSSION AND CONCLUSION}

On the eve of the arrival of the information age, information technology has been called a new paradigm inevitably impact on all areas of human knowledge and different social institutions has undergone great changes. Educational institutions in the face of this paradigm, based on new approaches, their educational system at various levels, setting them. The new paradigm is e-learning and information technology products for several years and is considered by some organizations and universities in several educational projects and even executed. Generally information technology has created new opportunities for communities;

Extra research on functional training is according to the system of distance education. Passing through the distance learning training system development stages so far that now we are faced with intelligent remote training system advantages with the disadvantages of this system of education and access to one of the responsibilities scholars and researchers clever is education.

According to the above-mentioned aim of this study point to the effectiveness of training in electronics than traditional learning by doing practical of theoretical training but due to lack of studio, lessons of the experiment (lighting of ) operations master was only through the picture and explain researcher Brian here with one of the disadvantages of theoretical practical courses, the remote system (not suitable for learning during the training) was facing That despite prepared for classes to this type of training should be kept in mind. The result of research indicate that in this type of training than traditional nursing Pardakhtchi (2012) was conducted so that the results were consistent, although both methods (electronic and traditional) are effective in raising awareness, but e-learning is not effective. Also, in another study by Esfahani and Mosallanezhad (2011) Have been carried out, the use of virtual systems for active learner in the learning ability and circuit training type of training due to the interaction of Medical Sciences, the system of learning is recommended, but in many practical skills, using traditional methods with modern methods, according to the new virtual training, is able to provide a context to deepen learned skills. In another study by Rabiei (2013) represents the electronic training of teachers to students is that more interest use of this type of training have shown. In another study, Bagheri Majd, Seyed Abbaszadeh, Mehr Alizadeh, Shahi (2012) results suggest that if e-learning with traditional training methods to be used more 
effectively to the learning effect and with regard to numerous advantages of e-learning, using it in training and retraining courses is recommended.

Korsli (2000), the electronic learning environment interaction between the learners teaching is done just absentia. In the presence of close interaction between people is done through verbal and nonverbal signs. But at the same time in the electronic environment of learning and teaching from a distance using verbal and nonverbal signals to communicate in a specific situation. Although both the use of these symptoms is similar, it should be noted that in the electronic environment through technology and communication at the same time this is done from a distance.

Seraji and Attaran, 2011)). E-teacher skills needed in three areas, the knowledge of educational issues and consider the interaction between them, three of applications, including; Technical knowledge of subject matter knowledge and technical training are nurturers. So what functions the teacher forms the technological knowledge of educational issues that arise from a combination of these sciences.

Mohammad, R., and Motenati, B. (2010) research on the impact of information technology in teaching and learning language A achieved the following results: much in common between the patterns of language teaching language teaching and learning pattern. The technology exists, management class has changed, activities, research-based teaching and learning and students traditional model centered open, decentralized, unlimited, leave the limits of time and space has become a strategy for the teaching and learning languages has brought results. Thus, despite being new to this type of training its outlook flow evolutionary evidence suggests that free dissemination of knowledge between countries could contribute to decreasing the differences between countries and underdeveloped countries in science because they can grow faster and free universal access to educational resources to accelerate the economic development, social will With the introduction of concepts such as e-commerce, e-government, e-learning and e-society in the communities; the use and application of information technology in various fields, further characterized._Bagheri Majd, Seyed Abbaszadeh, Mehr Alizadeh, Shahi (2014) in a study that concluded that e-learning for the development of educational content and appropriate evaluation, the system will be successful and efficient.

One of the most important issues that Iran is facing higher education, the traditional system of higher education responding to the real needs of society in the field of science and education effectively and efficiently. In the meantime, the topic of e-learning as a new, efficient, and effective teaching and learning in higher education is discussed. But this type of training, according to the discussions, the issues faced. According to research, the problems of e-learning development in the world are: lack of comprehensive educational policy and planning, infrastructure, language, capacity building and finance, pedagogical challenges, the challenge of organizational and technological challenges. With the advent of information technology in the field of education, many researchers have studied various aspects of research in the field of virtual education. In most of the research on organizational factors, infrastructure, facilities, planning, and policy development for e-learning is taken into consideration. (Bagheri Majd, Seyed Abbaszadeh, Yadollah, Mehr Alizadeh, Sekineh, Shahi (2014) 